\title{
Review
}

Respiration 2014;88:74-85

DOI: 10.1159/000360769
Received: June 27,2013

Accepted after revision: February 11, 2014

Published online: May 21, 2014

\section{Indwelling Pleural Catheters}

\author{
Rahul Bhatnagar Nick A. Maskell \\ Academic Respiratory Unit, School of Clinical Sciences, University of Bristol, Bristol, UK
}

\section{For editorial comment see p. 18}

\section{Key Words}

Catheters, indwelling · Pleural diseases · Pleural effusion

\begin{abstract}
Indwelling pleural catheters (IPC) are now established as one of the major tools for the management of recurrent pleural effusions. Their traditional role, which saw them only as second line treatment for malignant effusions, has now expanded. Recent evidence has not only suggested that they may be effectively employed as first-line therapy in some malignant cases, but that there is a wider spectrum of diseases which may be managed by their use. The majority of patients are likely to experience symptomatic benefit and some may also go on to achieve pleurodesis. IPCs are relatively simple to insert and maintain, and theoretically allow patients to be managed entirely as an outpatient, meaning that they are likely to be cost-effective in the longer term. They can also dramatically improve the quality of life in patients who have typically needed lengthy hospital admissions or who have terminal malignant disease.

(c) 2014 S. Karger AG, Basel
\end{abstract}

\section{Introduction}

Indwelling pleural catheters (IPCs) are now established as one of the major tools for the management of recurrent pleural effusions. Offering the potential of a completely outpatient-driven solution, their role has expanded from second-line treatment for malignant effusions with trapped lung or failed pleurodesis to include primary therapy for a number of conditions. IPCs are effective, both in terms of symptom control and costs, and can dramatically improve the quality of life for patients who have traditionally needed lengthy hospital admissions. This article looks to summarise the current knowledge regarding IPCs and explore where they sit in the modern management algorithms for pleural effusions, as well as how they may be used in the future.

\section{Background}

The modern iteration of an IPC is a multi-fenestrated chest drain made from a flexible silicone elastomer, with a small polyester cuff enveloping the medial portion of the tube. This latter part is tunnelled through a short section of subcutaneous tissue before the distal portion en-

Dr. Nick A. Maskell, DM, FRCP

Academic Respiratory Unit

School of Clinical Sciences, Learning and Research Building

University of Bristol, Southmead Hospital, Bristol BS10 5NB (UK)

E-Mail Nick.Maskell@Bristol.ac.uk 
ters the pleural space, with the cuff then acting as a focal point for fibrous growth to allow the drain to remain in place. At the proximal (external) end is a one-way access valve designed to be attached to proprietary vacuum drainage bottles. The most widely used device worldwide is the 15.5-Fr-diameter PleurX catheter, which is manufactured by CareFusion (McGaw Park, Ill., USA) and was first approved by the Food and Drug Administration in 1997 for use in malignant pleural effusions (MPEs) to relieve breathlessness and achieve pleurodesis [1]. This licence was extended 4 years later to include the drainage of all recurrent effusions [2].

Prior to this point, the traditional methods for managing recurrent pleural effusions were relatively limited and typically included admission to hospital for a chest tube (with or without chemical pleurodesis) or recurrent aspirations. Some centres were able to offer more extreme solutions, such as parietal pleurectomy or pleuro-peritoneal shunting, but these inevitably carried a risk of morbidity and were limited to patients who were fit enough to undergo general anaesthesia $[3,4]$.

The idea of directing a device subcutaneously to gain repeated, long-term access to the pleural space was initially approached in a number of ways. Some focussed on an implantable Port-a-Cath, with relatively good results - one group even being able to instil pleural immunotherapy in patients with mesothelioma [5]. Although relatively rare now, this approach still has favour in some parts of the world with one large series, published recently, showing low rates of complications and high rates of symptomatic relief [6]. A more recognisable precursor to the IPC was described in 1994. Robinson et al. [7] treated 9 patients with recurrent MPE, who had previously failed pleurodesis, with a Tenckhoff catheter, which was tunnelled into the pleural space under local anaesthesia. Support for the notion that chest tubes could be safely managed on an outpatient basis was also emerging at this time [8] and no doubt contributed to the idea that recurrent effusions could be drained in the home environment.

\section{IPC Insertion and Drainage}

\section{Indications}

The commonest indication for inserting an indwelling catheter remains malignancy, as this remains one of the leading causes of recurrent pleural effusions which are unlikely to respond to medical management [9]. The point during the malignant process at which to consider an IPC can be contentious as many practitioners feel that formal attempts at chemical pleurodesis should be the first-line approach [10], an argument which is explored in greater detail below.

Evidence also now exists to suggest they can be used to manage many other conditions, including non-malignant recurrent effusions [11], chylothorax [12, 13], loculated effusions [14], and even empyema [15] and haemothorax [16], although manufacturers still view some of these as contraindications [17]. Absolute contraindications include an inability for the patient, family or healthcare services to manage or tolerate the drain; uncorrected coagulopathy; pleural infection with evidence of ongoing sepsis, and evidence of cutaneous infection or significant malignant involvement over the proposed insertion site. Care should also be taken with patients who are persistently or repeatedly immunosuppressed. In the authors' view, all patients who have a symptomatic, recurrent pleural effusion who do not meet one of these exclusions should at least be considered for an IPC if the underlying diagnosis is either known or not required.

\section{Pre-Assessment and Consent}

Although occasionally inserted in inpatients, the majority of patients are able to undergo IPC insertion and management entirely in the outpatient setting [18]. Some practitioners may choose to stop routine anti-platelet therapy (except aspirin) up to 5 days before insertion. There are little data available to determine whether or not this is necessary, and although a recent report of 43 smallbore chest drains inserted while patients were on clopidogrel noted no instances of significant bleeding [19], we would still recommend stopping this prior to the procedure where possible.

\section{Insertion Technique}

IPCs may be inserted with the patient in almost any position which allows access to the fluid collection. The use of conscious sedation is preferred by some but is by no means mandatory, especially as drains can be safely inserted at the bedside if necessary [20]. It is our practice to have continuous oxygen saturation and pulse monitoring during the procedure.

The IPC is introduced into the pleural space using a modified Seldinger technique, having been tunnelled between two small skin incisions. These are usually created about 7-10 cm apart - which allows both easy access to the drain and sufficient length of tunnel to reduce the chances of dislodgement (fig. 1-4). It is important to note that the drain itself is not sutured in place; fixation relies upon tight closure of the skin incision through which the 


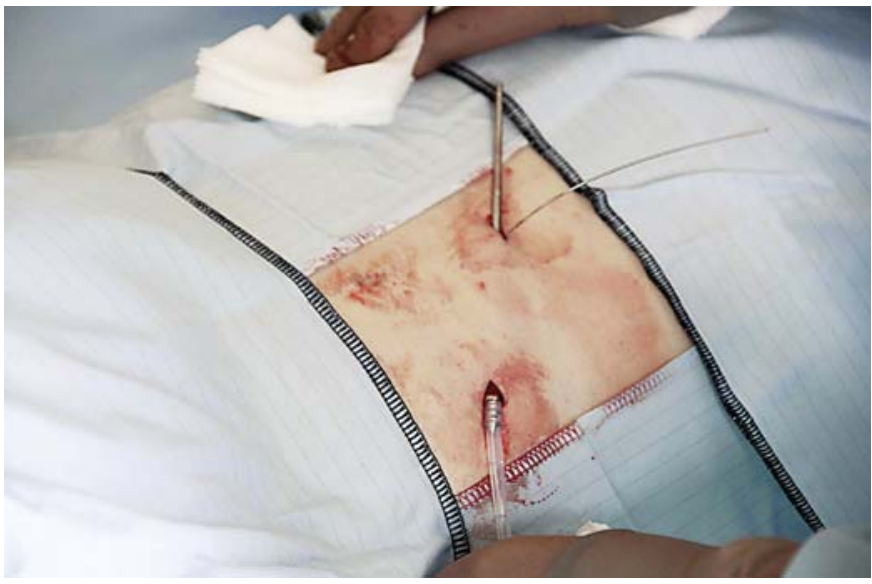

Fig. 1. Following the creation of two skin incisions and the placement of a Seldinger wire, the IPC is tunnelled under the skin. This can be achieved using a purpose-made dilator, seen here, or can simply be performed using blunt dissection of the subcutaneous tissues.

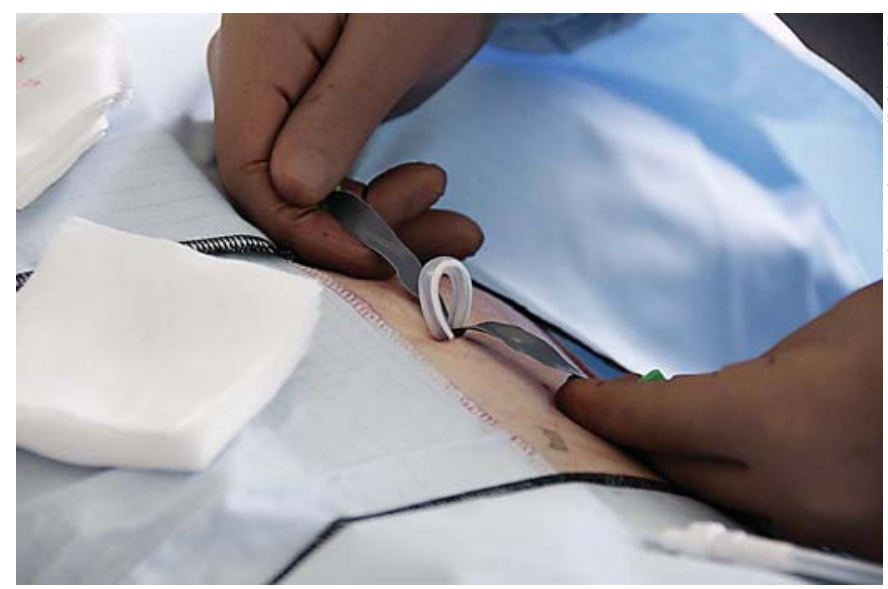

Fig. 3. A break-away dilator is used to place the fenestrated end of the IPC into the pleural space.

drain exits the subcutaneous tissues, as well as the eventual fibrosis around the cuff.

\section{Drainage Technique}

A typical initial IPC drainage frequency might be 3 times per week, with subsequent adjustment based upon volumes and drainage-associated symptoms. With a normal drainage lasting around $15 \mathrm{~min}$, it is possible for patients to maintain a high quality of life without significant disruption to home life. The fact that dressings are usually invisible under clothing also helps to dispel a com-

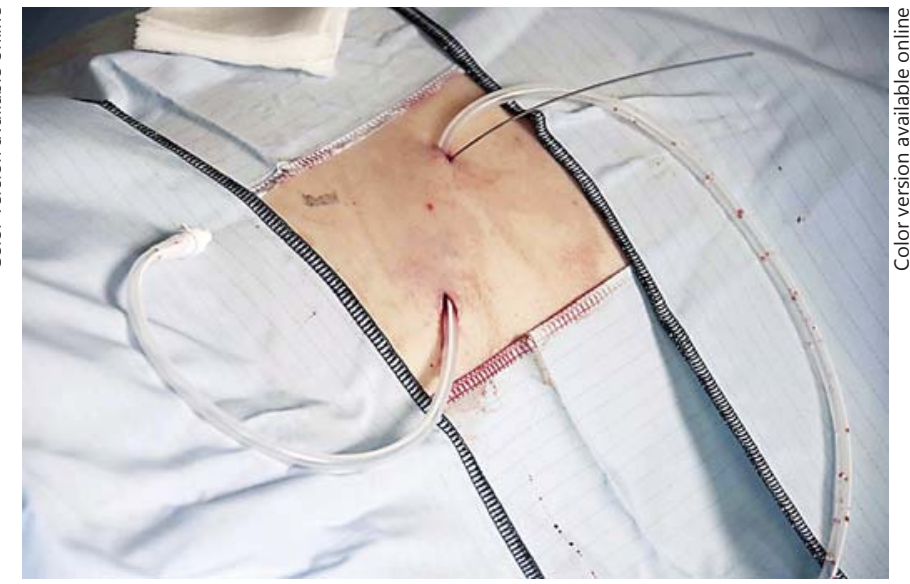

Fig. 2. A successfully tunnelled IPC.

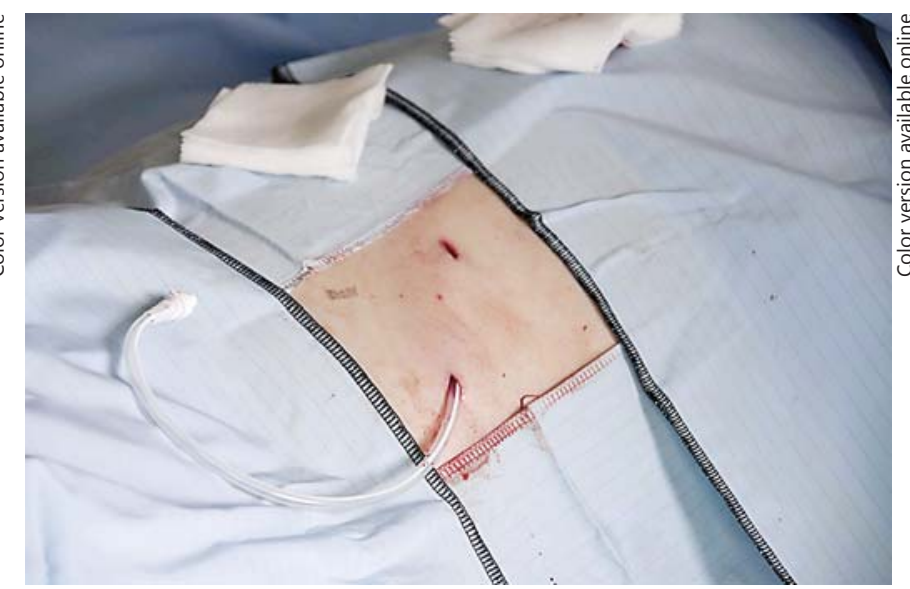

Fig. 4. A fully placed IPC. Two to three stitches will now be applied to the skin incisions to allow the drain to stay in place in the early stages of healing.

mon misconception that IPCs have to be cosmetically intrusive.

There are a number of similar devices which are currently marketed for use as IPCs, with each drained via a bag or bottle connected to a proprietary one-way access valve on the external portion of the drain. This container is primed with a vacuum in order to draw out the pleural contents, usually to a maximum of $500-1,000 \mathrm{ml}$ at a time.

Who manages an IPC in the community can vary significantly and is largely dependent on the provision of 
local services. Some centres provide early training to families and patients who then perform drainages at home with a named contact or emergency card in case of difficulty. [21] Others elect to utilise community nursing teams which, whilst perhaps less flexible than family-led drainage, allows those who do not have family support to have IPCs and provides patients with a more tangible safety net. Our practice combines these two; patients are discharged with the support of community nurses, and families or patients are then encouraged to take responsibility at a later date if appropriate.

Patients who require more sustained periods of pleural access following IPC insertion, perhaps for management of pleural infection, can usually have their drain accessed and attached to a standard underwater seal with the use of the correct adaptor set.

\section{Complications}

\section{Potential Early Complications}

Major complications resulting directly from IPC insertion are extremely rare [22] and there have been no reported cases of death associated with the procedure in any patient group.

On the post-procedure X-ray, it is common to see a small pneumothorax as a result of air being drawn into the chest during insertion, and this can usually be ignored. Such appearances may also be produced by trapped lung if significant volumes of fluid have been removed. Larger or unexpected collections of air should prompt consideration of underlying visceral damage and may warrant an extended period of observation before discharge. Instances of subcutaneous emphysema have also been documented, although many have occurred when an IPC is inserted at the same time as a video-assisted thoracic surgery (VATS) [23]. This demonstrates another reason why careful consideration should be given to track length, as if it is made too long there is the possibility of a fenestration remaining in the extrapleural space.

Pain can be an issue for some patients. A degree of discomfort in the days after insertion is to be expected and typically requires only simple analgesia. Significant pain should prompt concerns over intercostal nerve irritation and may, in extreme cases, even necessitate drain removal. Although discomfort may simply occur at the end of drainage, indicating a complete emptying of the pleural cavity, patients with trapped lung can also experience pain during drainage - sometimes to the extent whereby complete aspiration is impossible. This is a difficult situ- ation which may require routine premedication each time the system is accessed.

Other common early complications include drain dislodgement and bleeding. Dislodgement may occur more readily if the polyester cuff is sited too close to the skin incision, or if the patient has persistent episodes of coughing or retching. In terms of bleeding, a degree of localised bruising is expected in the region of the dissection track for a few days after insertion. However, persistent or marked haematoma or ooze may warrant further investigation. It is our practice to re-introduce usual anticoagulants immediately in the majority of patients.

\section{Long-Term Complications}

One of the major initial concerns about IPCs was the possibility that they may lead to pleural infection. Whilst there is undoubtedly a risk of this occurring, it remains small and should not dissuade patients or practitioners from inserting IPCs in those who require one. The two largest collections of IPC data currently available, one an abstract detailing the experience of infection in 10 centres [24] and the other a systematic review of 19 studies [25], and both containing cohorts of over 1,000 patients, reported pleural infection rates of 4.7 and $2.8 \%$ respectively, with the typical time to infection around 2 months after IPC insertion. The commonest organism cultured from pleural fluid in these circumstances appears to be Staphylococcus aureus, although one group noted that asymptomatic colonisation with other organisms, such as coagulase-negative staphylococci, may also occur [24, 26]. Table 1 shows a summary of outcomes, including pleural infection, from the use of IPCs in large series.

Those who do develop pleural infection rarely need drain removal or thoracic surgery. The majority, however, will require hospital admission for continuous drainage and intravenous antibiotics. Rosenstengel et al. [24] reported that of 49 such cases, $94 \%$ had successful treatment for their infection, with $26 \%$ needing intrapleural fibrinolytic therapy as an adjunct. Mortality was $0.3 \%$ in the overall cohort, all due to pleural infection.

Infection may also manifest locally around the insertion site, probably occurring in around 3\% of cases [25]. This usually resolves with simple oral antibiotic therapy but should be a prompt to ensure drain management techniques are appropriate.

If an IPC has been inserted because of malignancy, the local tissues may also be affected by tract metastasis. This usually occurs as a result of mesothelioma [27] but can occur in other malignancies [28]. Reported cases in the literature are sparse, but the incidence of metastasis oc- 
Table 1. Summary table of results from IPC series including $>100$ patients (with data available)

\begin{tabular}{lcclllll}
\hline First author & Year & $\begin{array}{l}\text { Total } \\
\text { patients }\end{array}$ & Population & $\begin{array}{l}\text { Empyema } \\
\text { incidence }\end{array}$ & $\begin{array}{l}\text { Pleurodesis } \\
\text { incidence }\end{array}$ & $\begin{array}{l}\text { Symptom } \\
\text { improvement }\end{array}$ & $\begin{array}{l}\text { Duration } \\
\text { of IPC }\end{array}$ \\
\hline Van Meter [25] & 2010 & 1,370 & mixed & $2.8 \%$ & $45.6 \%$ & $95.6 \%$ & 51 days \\
Rosenstengel [24] & 2012 & 1,036 & mixed & $4.8 \%$ & n/a & n/a & n/a \\
Suzuki [22] & 2011 & 418 & malignant & n/a & $26 \%$ & $91 \%$ & 44 days \\
Mekhaiel [84] & 2012 & 259 & malignant & $3.5 \%$ & n/a & n/a & 72 days \\
Mullon [11] & 2011 & 109 & non-malignant & $4.6 \%$ & $59 \%$ & $96 \%$ & 90 days \\
\hline
\end{tabular}

The study by Van Meter [25] is a systematic review of 19 series from 1994 to 2009.

curring appears to be just below 1\% [25]. Diagnosis can be made clinically or using ultrasound-guided biopsy [29], with radiotherapy treatment usually following. There is nothing to suggest that radiotherapy damages the IPC [27] and treatment, based upon small case series, tends to be successful, obviating the need for drain removal [28]. The question of whether there is a place for prophylactic radiotherapy in patients with mesothelioma undergoing IPC insertion remains unanswered, but trials are ongoing which will hopefully address this.

Some pleural processes can lead to inflammatory debris building up in an effusion. This then has the potential to cause blockage, which should always be suspected if there is cessation of fluid drainage. Larger series have demonstrated that occluded drains may be expected in $4 \%$ of cases [25,30], although one study recently reported as many as a fifth of IPCs were affected [31]. While cases can often be dealt with by saline flushes to clear any line obstruction, difficult occlusions can also be managed by the instillation of fibrinolytic therapy [32]. This approach may come at considerable expense, however, and does not guarantee avoidance of needing to reposition or replace the drain [33].

Mechanical failure of IPCs during routine care has also been reported and may occur in up to $2 \%$ of cases [25], with further instances in the literature of patients or carers accidentally damaging drains when accessing them [34]. This damage usually takes the form of the valve assembly becoming detached from the tubing, leaving a direct communication to the pleural space. While some IPCs are available with replacement valve kits in case of loss, this is not a universal feature. Some authors have described retrofitting this replacement kit onto rival manufacturers' catheters to maintain functionality (although this changes the type of drainage kit needed), or have cannibalised new IPC insertion sets to remove the valve in order to repair broken devices, with success reported using both approaches [35]. While repairing catheters in this way is certainly resourceful, removal with or without replacement of the IPC is the authors' firm recommendation, in order to keep the risk of developing pleural infection to a minimum.

The loss of electrolytes, immune factors or proteins has occasionally been raised as a concern of the long-term use of IPCs [10]. Information regarding this is relatively scarce, but there appears to be little to suggest that there is a risk of clinically significant shifts as a result of regular drainage of malignant effusions [36] or most non-malignant effusions [37]. A study by Fysh et al. [36] examined protein and albumin depletion in those with IPCs for MPE. After a 3-month follow-up, they were unable to demonstrate either significant reductions or between-group differences when comparing those with IPCs to those undergoing standard talc pleurodesis. Jimenez et al. [12] did note a statistically significant drop in albumin in a small series looking at chylothoraces requiring repeated drainage, but noted that patients did not require any nutritional supplementation. Albumin levels returned to normal upon removal of the IPC or cessation of regular thoracentesis.

\section{Use of IPCs in Malignant Pleural Disease}

MPEs are a significant and increasing burden to many healthcare providers. Estimates, which are likely to be conservative, suggest there are as many as 175,000 new cases of MPE each year in the US [38], the majority of which will be recurrent if not managed in a definitive manner. Survival of those diagnosed with MPE is poor overall, rarely being more than a few months [39], but possibly extending further in certain disease subgroups [40]. 


\section{IPCs as a First-Line Treatment}

The traditional management of an MPE focuses on fluid prevention (pleurodesis). Numerous pleurodesis agents have been used but the commonest and most efficacious is talc [41, 42], which may be instilled into the pleural space during thoracoscopy (poudrage) or via a standard chest tube after drainage of residual fluid. This would be expected to be successful around $70-80 \%$ of the time [41], although some series have been able to exceed this figure [43]. Debate continues as to which method of talc application is superior [44], but both require a period as a hospital inpatient, usually lasting up to a week [45]. In the minds of many patients with a shortened life expectancy and potentially ongoing cancer treatment, avoiding such an inpatient stay is of vital importance so as to maximise remaining quality of life.

The original role of IPCs was as a second-line management tool. IPCs were targeted at patients who had developed trapped lung and so would not successfully pleurodese; at those who had failed a pleurodesis in the past (perhaps because of high volume fluid production) and at those who had a shortened life expectancy. This position is still championed by a number of authors, with reasons for avoiding IPCs including raised long-term costs; low comparative rates of pleurodesis without talc, and higher complication rates [46-48].

In recent years, however, evidence has begun to mount for an alternative way of approaching recurrent MPE. This method dispenses with the notion that achieving pleurodesis is the priority, but instead looks to simply manage fluid as it builds up. IPCs are the ideal way to achieve this as they can be sited easily and quickly, and can be drained as often as is required to alleviate symptoms, allowing for consistent improvement in the breathlessness which will afflict the vast majority of patients with a malignant effusion [41], with improvements seen even in those with trapped lung [49]. In fact it is the improvement in dyspnoea, which occurs in over $90 \%$ of patients with IPCs placed for MPE [25], which led to the idea of offering IPCs as a first-line alternative to inpatient pleurodesis [50].

The case for fluid management alone, rather than attempted chemical pleurodesis, being part of the general algorithm for MPE has been advocated by a number of authors [51, 52]. Some suggest that IPCs should be a firstline treatment because they are able to provide a high level of patient and family empowerment [53] in conjunction with high levels of symptomatic relief, although there is a dearth of data addressing those with new-presentation MPE. Tremblay et al. [54] looked at over 100 patients who had undergone IPC insertion as a first-line therapy who would have been suitable for pleurodesis, and were able to show an improvement in symptoms in all patients 2 weeks after IPC insertion.

IPCs underwent a direct comparison with pleurodesis relatively soon after their approval, with Putnam et al. [55] comparing them to doxycycline via chest drain and concluding that they were an effective alternative treatment. However, it is a recent randomised controlled trial [31] which has perhaps been able to shed the most light on how IPCs may be used first line. In the TIME2 study, Davies et al. [31] compared the use of IPCs to standard talc slurry via chest drain in patients who had not previously undergone pleurodesis. The trial used self-reported dyspnoea scores as its main outcome measure, showing that 6 weeks after randomisation there was no significant difference between the two treatment arms. Some of the secondary endpoints appeared more favourable in the IPC group, including the proportion of patients who achieved a clinically significant relief in their symptoms ( 86 vs. $74 \%$ ); the median length of initial hospital stay ( 0 vs. 4 days), and the median number of days spent in hospital for drainage over the following 12 months ( 1 vs. 4.5 days). Although the study was not powered to address these directly, similar findings have been reported elsewhere [36]. The authors' conclusions were that IPCs may be viewed as a first-line therapy for MPE, not replacing talc pleurodesis but instead being offered to patients as a genuine alternative [31].

\section{IPCs and Spontaneous Pleurodesis}

Demmy et al. [56] undertook a similar randomised study to compare drain and talc to IPC insertion with daily drainage, but primarily analysed pleurodesis success at 30 days (which was made up of a composite of a number of outcomes including X-ray appearance) rather than dyspnoea. Insufficient accrual meant that only 58 patients could be analysed, and success rates in the talc arm were uncharacteristically low (45\%), but the overall conclusion was that IPCs were perhaps a better approach to palliation with a 'success' rate of $62 \%$ [56]. Such 'spontaneous' pleurodesis, whereby regular drainage leads to a reduction or cessation in fluid production, can occur even when IPCs are inserted for primarily symptomatic reasons. The typical way of recognising pleurodesis in those with IPCs is the repeated collection of small volumes of fluid (usually $50 \mathrm{ml}$ or less on 3 consecutive occasions), although some authors have defined it differently $[57,58]$. Collated data suggest an overall spontaneous pleurodesis rate of around 45\% for patients with MPE [25], however, some studies have reported significantly higher $[59,60]$ or low- 
er values $[14,61]$. This disparity highlights the important fact that patients with MPE tend to be an extremely heterogeneous group with regard to both fluid production and response to treatment. Those series with low pleurodesis rates have tended to focus on patients with a history of failed pleurodesis [20] or high-volume fluid production, both of which may infer a degree of trapped lung. A subgroup analysis of a 250-patient cohort revealed that the pleurodesis rate in such patients was only $25 \%$, compared to $57 \%$ in those who had no surrogate markers for trapped lung [50]. Patients with certain subtypes of disease, for example haematological malignancies, may also have a tendency to pleurodese less readily [61]. Higher pleurodesis rates, often exceeding $70 \%$, have been noted when more aggressive drainage regimens (daily or more frequent) have been used, or when patients undergo a talc pleurodesis at the same time as IPC insertion [60]. This latter approach has typically been the domain of surgeons who are performing VATS for biopsy of suspected malignant disease, although this practice is beginning to expand to some medical thoracoscopists. In a small pilot series, Reddy et al. [58] were able to demonstrate pleurodesis success rates of $92 \%$, and a median IPC duration of just over 7 days when performing local anaesthetic thoracoscopy, talc poudrage and IPC placement in a single session, followed by aggressive drainage.

This latter combination approach demonstrates the modern, and increasing, versatility of diagnostic and therapeutic techniques. However, patients with a malignant effusion are able to present at varying points along their disease spectrum meaning the management options available have the potential to be both confusing and overwhelming. Adapting to a patient's wishes and symptoms while balancing the need for histological samples is paramount, and IPCs have a major role in allowing this. A potential treatment algorithm, which recognises the IPC as a valid, important first-line treatment, is shown in figure 5 .

\section{IPCs and Chemotherapy}

As demonstrated, the use of an IPC is likely to improve a patient's dyspnoea, and hence their performance status and potentially their eligibility for chemotherapy. Despite this, there has historically been a concern that patients receiving chemotherapy with an IPC in situ may suffer with an excess of infective adverse events. A retrospective analysis of over 170 chemotherapy patients, however, was not able to demonstrate a significant difference in pleural infection rates when compared to those who did not receive chemotherapy [62], a finding replicated in at least two other series which have addressed the same question
$[26,63]$. The authors of all these studies conclude that an IPC should not preclude the use of chemotherapy if needed. The decision to insert an IPC in a patient who is already undergoing anti-cancer therapy may be more complex, and often requires careful liaison with oncologists to ensure insertion does not coincide with a period of neutropenia or significant thrombocytopenia, both of which would be contraindications.

\section{Future of IPCs in Malignant Disease}

With evidence supporting the use of IPCs over many months or even years if managed correctly, they are increasingly being seen as an appealing conduit for intrapleural therapy. It is well established that fibrinolytic agents such as urokinase can be used to unblock occluded lines, including IPCs, but it is now increasingly common to give larger doses of fibrinolytics to the pleural space in an attempt to improve fluid drainage in the event of malignant loculation [51], and a randomised trial is currently underway looking to see if such treatment can improve pleurodesis in these cases. It could also be argued that, in some patients with loculated effusions, insertion of an IPC with a plan to give immediate fibrinolytics may be the optimal treatment.

IPCs also hold the potential to allow direct anti-cancer therapy. Reports of this are scarce but nonetheless demonstrate that treatment can be applied to a range of conditions: Sterman et al. $[64,65]$ showing that patients with MPE or mesothelioma can be safely given both single- and repeated-dose interferon- $\beta$ gene therapy and another group reporting the administration of monthly rituximab via an IPC for a patient with non-Hodgkin's lymphoma [66]. This latter case was able to demonstrate not only resolution of the effusion but enough systemic absorption of the drug to induce partial remission. Other investigators have also used IPCs to administer novel pleurodesis agents and accurately monitor the pleural space reaction [67].

In fact, the combination of IPCs and pleurodesis agents may well have the potential to significantly alter the paradigm of MPE management by allowing patients to achieve the best of both worlds - high levels of autonomy and outpatient care, along with higher rates of pleurodesis than would be expected using an IPC alone, with a multicentre randomised study already underway to explore this possibility. Talc has previously been given via IPCs on a case-by-case basis in patients who have ongoing high-volume output [54], and there have been reports of alternative agents being administered intrapleurally, including bleomycin and doxycycline in one uncompleted randomised trial [68]. 


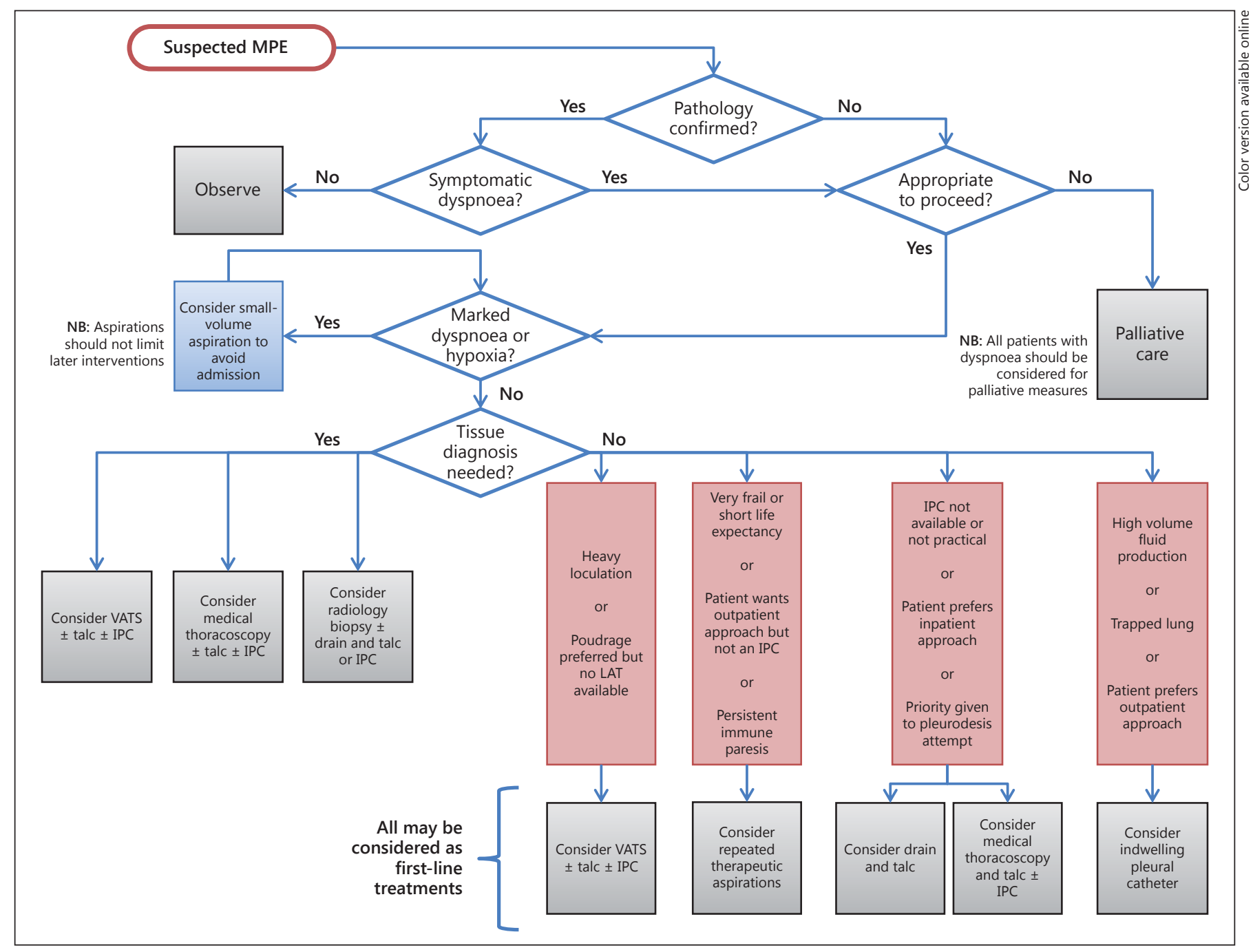

Fig. 5. A potential algorithm describing the various options for the management and investigations in patients with MPE. LAT $=$ Local anaesthetic thoracoscopy.

One step beyond intrapleural drug delivery via the tube is to increase the irritation that the IPC itself causes to the pleural space. Pleurodesis agents are usually given as a larger, single-dose treatment because repeated administration often requires extended periods in hospital, a problem potentially solved by IPCs. Tremblay et al. [69] have demonstrated that low-level, repeated doses of intrapleural silver nitrate in a rabbit model can maintain the pleurodesis efficacy of a drug without raising the side effect profile. The same group then went on to show that this agent can be coated onto an IPC to create a silver nitrate-eluting catheter, which can safely induce pleurodesis in rabbit and lamb models [70].

Indwelling Pleural Catheters

\section{Use of IPCs in Non-Malignant Disease}

Although effusions from non-malignant causes are common, there is relatively little information regarding the use of IPCs in these situations, with limited data only beginning to emerge in the last 3-4 years. This may be because patients with conditions such as congestive cardiac failure or hepatic hydrothorax are less likely to be managed by physicians who are familiar with pleural interventions, and, perhaps a result, there remains a high level of concern for introducing infection into the pleural space [71]. In the case of patients with ascites, there is also the risk of allowing infection to track trans-diaphragmatically into the abdomen. 
Harris and Chalhoub [37] analysed data from 146 patients across 9 small studies and demonstrated that there remains not only significant heterogeneity between the types of effusions being managed, but also among the experiences of those managing the IPCs. Patient improvement, when reported, was of a similar level to that seen in MPE (94\%) although the duration of the IPC being in situ was often longer, with an associated delay to spontaneous pleurodesis. Chalhoub et al. [59] compared the outcome of a small cohort of patients with non-malignant IPCs to those with one with malignancy, demonstrating an average time to pleurodesis of over 3 months compared to just 36 days in the malignant group. Despite this potentially extended period of use, complications do not appear to occur significantly more often than in the malignant population, with an overall incidence of $11 \%$ and a specific empyema incidence of $5 \%$ [37]; this latter figure being confirmed by large series from both the US and the UK $[11,85]$. The proportion of patients undergoing spontaneous pleurodesis appears to vary greatly between series. Mullon et al. [11] noted a drain removal percentage of over $60 \%$ within their cohort, with the majority needing an IPC due to heart failure. However, a more recent study comprising solely those with cardiogenic effusions had a pleurodesis rate of only $29 \%$. This figure was more in line with a multicentre series by our own group, which suggested that the sub-aetiologies of non-malignant effusions can have a significant influence on outcomes. This study, which contained a high number of patients with hepatic hydrothorax, was able to demonstrate that not only did liver disease patients produce significantly more fluid than those with other conditions but also that these same patients were far less likely to achieve pleurodesis [85].

Patients with hepatic hydrothoraces have been the focus of calls for increased research [72] because this population often has a limited range of therapeutic options available to them, as well as having a tendency to suffer from large compromising effusions. Small-scale studies are beginning to allay fears of excess infection rates and the loss of protein or electrolytes, although mortality from the underlying liver condition remains extremely high $[37,71,73]$. As such, there is now a growing recognition that IPCs can be an aid to palliation in those liver failure patients unfit for transplant or intrahepatic shunts, and as well as acting a bridge to surgery for others.

\section{Removal of IPCs and Associated Complications}

As described above, a reduction in the volumes of fluid being drained may occur with an IPC if it is left in place long enough. Spontaneous pleurodesis is one of a number of potential reasons for considering removal of a catheter, along with irremediable blockage or pleural loculation; significant pleural infection; pain, either due to drainages or the presence of the drain itself, or damage to the IPC itself.

Since the polyester cuff attached to the drain is designed to promote local fibrosis, the removal of a drain can become more difficult the longer it is left in situ. Particularly aggressive malignant pleural processes can also lead to fibrotic bands growing through IPC fenestrations or along its surface, making extraction particularly challenging. The most important part of the procedure is the careful dissection of the fibrous material around the cuff following appropriate incisions. Gradual but firm pressure can then be applied to the proximal end of the IPC to encourage dislodgement.

For some patients, the internal pulling sensation may be too much to tolerate, meaning the drain cannot be safely removed. In this situation, an alternative to simply leaving the drain is to only remove the proximal portion. This is achieved by severing the IPC while under tension, which causes the distal end to recoil back into the pleural space. Fysh et al. [74] described 2 cases of this being undertaken in a small series of complicated removals. They also note that segments of drain may also be left behind following accidental fracture during removal, which may occur if too much tension is applied or if a drain has been damaged previously. In none of the cases in which tubing was left intrapleurally did the patient experience any infective or pain-related complications during follow-up.

\section{Cost of IPCs}

One of the most appealing aspects of allowing patients with effusions to be managed entirely as outpatients is the potential for saving the considerable expense associated with prolonged or repeated hospital admissions. There is little argument that IPCs significantly reduce the number of inpatient days required to both initially treat and manage pleural effusions $[75,76]$, but translating this into to direct cost savings can be more tricky. The immediate costs of an IPC insertion are relatively low, but begin to accumulate as consumable drainage bottles are used over the longer term. Given that the majority are inserted for 
patients with reduced life expectancy and high morbidity, total costs alone are less useful than quality-adjusted measures when determining how to allocate resources.

Several studies have attempted to address this issue, but most are limited either by the need to infer utility data from non-MPE or non-IPC patient groups, or by the use of models which are divergent from common clinical practice [77-80]. The first study to look closely at the cost-effectiveness of IPCs was performed by Olden and Holloway [78] in 2010, who compared the PleurX drain to chest drain and talc slurry. They concluded that the overall costs and cost-effectiveness (in terms of qualityadjusted life years) of both arms were similar, but that IPCs became more effective when patients have a life expectancy of 6 weeks or less, based on a thrice-weekly drainage regimen. Weaknesses of this analysis, however, include the use of peritoneal dialysis patients to inform utility data, and the unusual assumption than $10 \%$ of patients would fail an IPC and go on to have talc slurry, as well as the non-inclusion of alternative modes of treatment such as thoracoscopy [78].

An alternative breakdown was performed more recently by Puri et al. [79], again looking at talc slurry and IPCs, but also including VATS pleurodesis and recurrent thoracentesis. In their model, which conservatively assumes an IPC success rate of $40 \%$; once weekly drainage, as well as drainage by family in $50 \%$ of cases, IPCs were again found to be the superior method in the short term - this time after 3 months of treatment. In patients surviving out to 1 year, bedside pleurodesis appeared to be the most cost-effective modality. The only study, published as an abstract, to include medical thoracoscopy as a separate treatment was also in favour of IPCs in the short term [77].

There is a considerable amount of work still needed to fully elucidate the true comparative effectiveness and costs of IPCs, both in lone use and in combination with other treatments. This is especially important as there is increasing recognition that individual malignancies, as well as non-malignant causes of effusions, can lead to highly divergent life expectancies [81] and hence expected time with an IPC in place.

The direct costs of IPCs, along with less-well-established healthcare infrastructure, have meant that there has been relatively little uptake of their use in the developing world, with some authors introducing novel methods to try to address this. Al-Halfawy and Light [82] have described the use of patient-maintained, re-usable surgical vacuum pumps to drain IPCs on a routine basis in Egypt, leading to a remarkably high incidence of pleurodesis and monthly consumable costs more than one hundred times lower than normal. In addition, akin to the early days of experimenting with methods of repeated pleural drainage, a group from Thailand has recently used a tunnelled Jackson drain instead of a purpose-made IPC, with promising results [83].

\section{Conclusion}

IPCs have now become a mainstay of treatment for recurrent effusions since their introduction over 15 years ago. Having initially been relegated to those with trapped lung or in whom attempts at chemical pleurodesis had failed, consistently low rates of complications, reduced inpatient stay and the recognition that significant improvements in patients' symptoms were possible have meant that they can now be viewed as a genuine, first-line management strategy. They are relatively easy to insert, manage and remove, and provide the ability to empower patients in both the decisions regarding their treatment and the management of their disease itself.

Although much of the literature on which IPC use is based is retrospective in the form of case series, there is now an increasing drive to undertake randomised studies. These may well have the ability to further challenge the traditional management paradigms even further by endorsing treatment regimens which include IPCs alongside chemical pleurodesis, perhaps doing away with the need for inpatient stays for recurrent effusions altogether. Further studies into the long-term costs and effectiveness of IPCs are required, as well as into their effects and utility in more specific subgroups of patients. However, it can be said without doubt that IPCs, in the management of recurrent pleural effusions, are generally safe, well tolerated and efficacious in the relief of patient symptoms.

\section{Financial Disclosure and Conflict of Interest}

Dr. Bhatnagar has received lecture fees from AstraZeneca and GlaxoSmithKline, and educational grants from Novartis and GlaxoSmithKline. Dr. Maskell has received unrestricted research grants from Novartis and CareFusion. He has also received honoraria from CareFusion for medical advisory board meetings. Dr. Bhatnagar and Dr. Maskell have no conflicts of interests to declare. 


\section{References}

1 Summary of Safety and Effectiveness Denver PleurX Pleural Catheter Kit, Denver PleurX Home Drainage Kit. Rockville, Food \& Drug Administration, 1997.

2 PleurX Pleural Catheter and Drainage Kits. Rockville, Food \& Drug Administration, 2001.

-3 Fry WA, Khandekar JD: Parietal pleurectomy for malignant pleural effusion. Ann Surg Oncol 1995;2:160-164.

4 Genc $\mathrm{O}$, et al: The long-term morbidity of pleuroperitoneal shunts in the management of recurrent malignant effusions. Eur J Cardiothorac Surg 2000;18:143-146.

-5 Driesen P, et al: Implantable access system for prolonged intrapleural immunotherapy. Eur Respir J1994;7:1889-1892.

6 Kriegel I, et al: Use of a subcutaneous implantable pleural port in the management of recurrent malignant pleurisy: five-year experience based on 168 subcutaneous implantable pleural ports. J Palliat Med 2011;14:829834.

7 Robinson RD, et al: Use of pleural Tenckhoff catheter to palliate malignant pleural effusion. Ann Thorac Surg 1994;57:286-828.

-8 Ponn RB, Silverman HJ, Federico JA: Outpatient chest tube management. Ann Thorac Surg 1997;64:1437-1440.

-9 Hooper C, et al: Investigation of a unilateral pleural effusion in adults: British Thoracic Society Pleural Disease Guideline 2010. Thorax 2010;65(suppl 2):ii4-ii17.

10 Aelony Y: Tunnelled pleural catheters in malignant pleural effusion - author's reply. Lancet 2007;370:387.

11 Mullon J, Maldonado F: Use of tunneled indwelling pleural catheters for palliation of nonmalignant pleural effusions. Chest 2011; 140:996A.

12 Jimenez CA, et al: Use of an indwelling pleural catheter for the management of recurrent chylothorax in patients with cancer. Chest 2007;132:1584-1590.

13 Depew ZS, et al: The role for tunneled indwelling pleural catheters in patients with persistent benign chylothorax. Am J Med Sci 2013;346:349-352.

14 Thornton RH, et al: Tunneled pleural catheters for treatment of recurrent malignant pleural effusion following failed pleurodesis. J Vasc Interv Radiol 2010;21:696-700.

$\checkmark 15$ Davies HE, et al: Use of indwelling pleural catheters for chronic pleural infection. Chest 2008;133:546-549.

16 Almeida FA, et al: Hemothorax treated with indwelling tunneled pleural catheter: are all hemothoraces the same? J Bronchology Interv Pulmonol 2011;18:261-264.

17 CareFusion, PleurX Pleural Catheter Mini Kit information leaflet. McGaw Park, CareFusion, 2011, p 4.

18 Morgan L, et al: PleurX catheters provide safe and effective control of malignant pleural effusion. Respirology 2012;17:68.
19 Dammert P, Pratter M, Boujaoude Z: Safety of ultrasound-guided small-bore chest tube insertion in patients on clopidogrel. J Bronchology Interv Pulmonol 2013;20:16-20.

20 Sioris T, et al: Long-term indwelling pleural catheter (PleurX) for malignant pleural effusion unsuitable for talc pleurodesis. Eur J Surg Oncol 2009;35:546-551.

21 Maguire J, Rutherford L, Robinson A: 'Better safe than sorry' - improving practice by the introduction of a PleurX catheter 'Alert' card. Lung Cancer 2010;67:S28.

22 Suzuki K, et al: Palliation and pleurodesis in malignant pleural effusion: the role for tunneled pleural catheters. J Thorac Oncol 2011; 6:762-767.

23 Qureshi RA, et al: Management of malignant pleural effusion associated with trapped lung syndrome. Asian Cardiovasc Thorac Ann 2008; 16:120-123.

24 Rosenstengel A, et al: Pleural infections associated with indwelling pleural catheters (IPC). Respirology 2013;18:31.

25 Van Meter MEM, McKee KY, Kohlwes RJ: Efficacy and safety of tunneled pleural catheters in adults with malignant pleural effusions: a systematic review. J Gen Intern Med 2011;26: 70-76.

$\checkmark 26$ Morel A, et al: Chemotherapy should not be withheld from patients with an indwelling pleural catheter for malignant pleural effusion. Thorax 2011;66:448-449.

27 West SD, Foord T, Davies RJO: Needle-track metastases and prophylactic radiotherapy for mesothelioma. Respir Med 2006;100:10371040.

28 Janes SM, et al: Catheter-tract metastases associated with chronic indwelling pleural catheters. Chest 2007;131:1232-1234.

29 Riker D, Sell R: Ultrasound-guided percutaneous biopsy to diagnose indwelling pleural catheter metastasis. J Bronchology Interv Pulmonol 2012;19:165-167.

>30 Warren WH, Kim AW, Liptay MJ: Identification of clinical factors predicting PleurX catheter removal in patients treated for malignant pleural effusion. Eur J Cardiothorac Surg 2008;33:89-94.

31 Davies HE, et al: Effect of an indwelling pleural catheter vs chest tube and talc pleurodesis for relieving dyspnea in patients with malignant pleural effusion: the TIME2 randomized controlled trial. JAMA 2012;307:2383-2389.

32 Murthy SC, et al: A simple solution for complicated pleural effusions. J Thorac Oncol 2006;1:697-700.

33 Borgeson DD, et al: Chronic indwelling pleural catheters reduce hospitalizations in advanced heart failure with refractory pleural effusions. J Card Fail 2009;1:S105.
34 Nasim F, Folch E, Majid A: Tunneled pleural catheter dysfunction: case report and review of complications. J Bronchology Interv Pulmonol 2012;19:149-152.

35 Bower C, Mahmood K: Re: Noninvasive repair of broken tunneled pleural catheters. J Vasc Interv Radiol 2011;22:255-256.

-36 Fysh ETH, et al: Indwelling pleural catheters reduce inpatient days over pleurodesis for malignant pleural effusion. Chest 2012;142: 394-400.

37 Harris K, Chalhoub M: The use of a PleurX catheter in the management of recurrent benign pleural effusion: a concise review. Heart Lung Circ 2012;21:661-665.

-38 American Thoracic Society: Management of malignant pleural effusions. Am J Respir Crit Care Med 2000;162:1987-2001.

-39 Heffner JE, Nietert PJ, Barbieri C: Pleural fluid $\mathrm{pH}$ as a predictor of survival for patients with malignant pleural effusions. Chest 2000. 117:79-86.

40 Pilling JE, et al: Prognostic factors for survival after surgical palliation of malignant pleural effusion. J Thorac Oncol 2010;5:1544-1550.

41 Roberts ME, et al: Management of a malignant pleural effusion: British Thoracic Society Pleural Disease Guideline 2010. Thorax 2010; 65(suppl 2):ii32-ii40.

42 Shaw P, Agarwal R: Pleurodesis for malignant pleural effusions. Cochrane Database Syst Rev 2004;1:CD002916.

43 Viallat JR, et al: Thoracoscopic talc poudrage pleurodesis for malignant effusions. A review of 360 cases. Chest 1996;110:1387-1393.

44 Dresler CM, et al: Phase III intergroup study of talc poudrage vs talc slurry sclerosis for malignant pleural effusion. Chest 2005;127:909915.

45 Yim AP, et al: Thoracoscopic talc insufflation versus talc slurry for symptomatic malignant pleural effusion. Ann Thorac Surg 1996;62: 1655-1658.

46 Kaifi JT, et al: Multidisciplinary management of malignant pleural effusion. J Surg Oncol 2012;105:731-738.

47 Zahid I, et al: What is the best treatment for malignant pleural effusions? Interact Cardiovasc Thorac Surg 2011;12:818-823.

48 Antevil JL, Putnam JB Jr: Talc pleurodesis for malignant effusions is preferred over the PleurX catheter (pro position). Ann Surg Oncol 2007;14:2698-2699.

49 Efthymiou CA, et al: Malignant pleural effusion in the presence of trapped lung. Five-year experience of PleurX tunnelled catheters. Interact Cardiovasc Thorac Surg 2009;9:961964.

50 Tremblay A, Michaud G: Single-center experience with 250 tunnelled pleural catheter insertions for malignant pleural effusion. Chest 2006;129:362-368.

-51 Khaleeq G, Musani AI: Emerging paradigms in the management of malignant pleural effusions. Respir Med 2008;102:939-948. 
52 Scheule AM, Wiest E: Experience of 359 patients after implantation of tunneled indwelling pleural catheter (PleurX) in management of malignant pleura effusion: who provides the indication and who performs the implantation? Onkologie 2011;34:29.

53 Warren W: Talc pleurodesis for malignant pleural effusions is preferred over the PleurX catheter (contrary position). Ann Surg Oncol 2007;14:2700-2701.

54 Tremblay A, Mason C, Michaud G: Use of tunnelled catheters for malignant pleural effusions in patients fit for pleurodesis. Eur Respir J 2007;30:759-762.

55 Putnam JB, et al: A randomized comparison of indwelling pleural catheter and doxycycline pleurodesis in the management of malignant pleural effusions. Cancer 1999;86: 1992-1999.

56 Demmy TL, et al: Comparison of in-dwelling catheters and talc pleurodesis in the management of malignant pleural effusions. J Clin Oncol 2010;28:15s.

-57 Bertolaccini L, et al: Home-management of malignant pleural effusion with an indwelling pleural catheter: ten years experience. Eur J Surg Oncol 2012;38:1161-1164.

58 Reddy C, et al: Rapid pleurodesis for malignant pleural effusions: a pilot study. Chest 2011;139:1419-1423.

59 Chalhoub M, et al: The use of the PleurX catheter in the management of non-malignant pleural effusions. Chron Respir Dis 2011;8: 185-191.

60 Bazerbashi S, et al: Ambulatory intercostal drainage for the management of malignant pleural effusion: a single center experience. Ann Surg Oncol 2009;16:3482-3487.

-61 Shah A, et al: Tunneled indwelling pleural catheters in hematologic malignancies. Chest 2011;140:702A.

62 Mekhaiel E, et al: Infections associated with tunnelled indwelling pleural catheters in patients undergoing chemotherapy. J Bronchology Interv Pulmonol 2013;20:299-303.

63 Sachdeva A, et al: Risk of infectious complications with tunneled pleural catheter in patients undergoing chemotherapy. Chest 2012; 142:522a.
64 Sterman DH, et al: A phase I clinical trial of single-dose intrapleural IFN-beta gene transfer for malignant pleural mesothelioma and metastatic pleural effusions: high rate of antitumor immune responses. Clin Cancer Res 2007;13:4456-4466; erratum Kanther M, Clin Cancer Res 2007;13:5226.

65 Sterman DH, et al: A phase I trial of repeated intrapleural adenoviral-mediated interferonbeta gene transfer for mesothelioma and metastatic pleural effusions. Mol Ther 2010;18: 852-860.

66 Islam A, Takita H: Malignant pleural effusion and advanced stage low-grade non-Hodgkin's lymphoma successfully treated with intrapleural instillation of rituximab. Blood 2012;120:4891.

67 Rahman NM, et al: Use of lipoteichoic acid-T for pleurodesis in malignant pleural effusion: a phase I toxicity and dose-escalation study. Lancet Oncol 2008;9:946-952.

68 Barrett D, et al: Double-blind randomized comparison of bleomycin \& doxycycline administered via an indwelling pleural catheter for malignant pleural effusions (MPE) (abstract). Am J Respir Crit Care Med 2002, A606.

69 Tremblay A, Stather DR, Kelly MM: Effect of repeated administration of low-dose silver nitrate for pleurodesis in a rabbit model. Respirology 2011;16:1070-1075.

70 Tremblay A, et al: Use of a drug eluting pleural catheter for pleurodesis. Exp Lung Res 2012;38:475-482.

71 Imler T, et al: To drain or not drain: PleurX indwelling drainage catheters for non-malignant refractory ascites or hepatic hydrothorax. Am J Gastroenterol 2012;107:S145.

72 Kilburn JP, et al: Use of indwelling tunneled pleural catheters for the management of hepatic hydrothorax. Chest 2010;138:418A.

73 Bhatnagar R, et al: P123 The use of indwelling pleural catheters for the management of nonmalignant recurrent pleural effusions. Thorax 2012;67(suppl 2):A115.

74 Fysh ETH, et al: Fractured indwelling pleural catheters. Chest 2012;141:1090-1094.
Munson CF, et al: Indwelling pleural catheters reduce inpatient stay for patients with malignant pleural effusion. Lung Cancer 2011;71:S16-S17.

76 Fysh ET, Musk B, Lee YG: Patients with malignant pleural effusions who undergo talc pleurodesis spend more days in hospital than those with indwelling pleural catheters. Am J Respir Crit Care Med 2011;183:A3083.

77 Michaud G, et al: Cost effectiveness analysis of strategies for managing malignant pleural effusions. Am J Respir Crit Care Med 2011; 183:A3082.

78 Olden AM, Holloway R: Treatment of malignant pleural effusion: PleuRx catheter or talc pleurodesis? A cost-effectiveness analysis. J Palliat Med 2010;13:59-65.

79 Puri V, et al: Treatment of malignant pleural effusion: a cost-effectiveness analysis. Ann Thorac Surg 2012;94:374-379; discussion 379-380.

80 Haas AR, Sterman DH, Musani AI: Malignant pleural effusions: management options with consideration of coding, billing, and a decision approach. Chest 2007;132:1036-1041.

81 Clive A, et al: S16 A large, prospective, multicentre study evaluating the survival of patients with malignant pleural effusion according to the underlying cell type. Thorax 2012; 67(suppl 2):A10-A11.

82 Al-Halfawy A, Light R: Safety and efficacy of using a surgivac pump for the drainage of chronic indwelling pleural catheters in malignant pleural effusions. Respirology 2008; 13 : 461-464.

83 Tscheikuna J, Thomrongpairoj P, Disayabutr $S$ : The efficacy of Jackson drain in the application to be a tunnel pleural catheter (TPC) in the management of malignant pleural effusion. J Med Assoc Thai 2011;94:679-685.

84 Mekhaiel E, et al: Incidence of infection among patients on chemotherapy with tunneled indwelling pleural catheters. Chest 2012;142:523a.

85 Bhatnagar R, Reid ED, Corcoran JP, et al: Indwelling pleural catheters for non-malignant effusions: a multicentre review of practice. Thorax 2013. DOI: 10.1136/thoraxjnl-2013204563, Epub ahead of print. 